\title{
Phytochemical screening and biological activities of Aloe vera (L.) Burm. F.
}

Bibi Raad ${ }^{1}$, Syed Shaukat Ali $^{1}$, Khushnood Ur Rehman ${ }^{2}$, Naveed Akhtar $^{2}$, Barkat Ullah ${ }^{2}$ and Sher Wali ${ }^{*}$

1. Department of Chemistry, Islamia College, Peshawar-Pakistan

2. Department of Botany, Islamia College, Peshawar-Pakistan

*Corresponding author's email: sherwali@icp.edu.pk

Citation

Bibi Raad, Syed Shaukat Ali, Khushnood Ur Rehman, Naveed Akhtar, Barkat Ullah and Sher Wali. Phytochemical screening and biological activities of Aloe vera (L.) Burm. F. Pure and Applied Biology. Vol. 10, Issue 2, pp360367. http://dx.doi.org/10.19045/bspab.2021.100039

\begin{tabular}{llll}
\hline \hline Received: 20/11/2019 & Revised: 07/07/2020 & Accepted: 12/08/2020 & Online First: 29/09/2020 \\
\hline \hline
\end{tabular}

\section{Abstract}

In the present work phytonutrients including tannins, phlobatannins, flavonoids, saponins, cardiac glycosides and terpenoids were investigated in Aloe vera plant. Leaves of Aloe vera were chosen for this investigation. The plants were collected from the botanical garden of Islamia College, Peshawar. The phytochemicals were determined quantitatively using different solvents. The leaves were also investigated to find its antibacterial and antifungal activities. All the photochemicals excepting Phlobotannins were found in all the extracts. Results revealed very profound activities of the plant extracts against the tested gram positive strains including Staphylococcus aureus, Bacillus subtilis, Bacillus atrophoeus and gram negative bacterial strains i.e. Escherichia coli, Klebsiella pneumoniae, Salmonella typhi. The extracts also showed considerable activity against the tested fungal strains Aspergillus flavus, Aspergillus niger and Candida albicans.

Keywords: Alkaloids; Aloe vera; Cardiac Glycosides; Escherichia coli; Phlobatannins;

Staphylococcus aureus; Steroids

\section{Introduction}

Aloe is described to be a very useful in curing infections, laxative and skin problems in the form of Mesopotamian tablets and ancients Egyptians papyrus [1]. Aloe cream is said to be included in the beauty items of Cleopatra [2]. It has been used by the Arabian physicians and Hippocrates. It was carried by the Spanish globetrotters to the western hemisphere. It is also on record that the Socotra Island in Indian Ocean was captured by Alexander for securing the supplies of Aloe which were used for the treatment of injured soldiers [3]. Ayurveda and traditional Chinese medicine have given
Aloe great popularity. In Chinese medicine its skin and inner layer of leaves is described as a bitter cold recipe which is used to cure constipation because of heat accumulation; while its gel is moist and cold [4]. According to India's traditional medicine, Ayurveda, it is internally used as antihelminthic, laxative, uterine stimulant and a remedy against hemorrhoid. Externally it is used for the treatment of psoriasis and eczema, often in combination with licorice roots. Its gel is used to relief headache, coolant, laxative, disinfectant, anti-conjunctivitis and wood healing agent in Arabian medicine [5]. Nowadays the gel 
obtained from Aloe vera plant serves to be the active component in cosmetics, sunblocks and skin lotions [6]. Its uses have been enormously increased in cosmetics based on the arguments that it has anti-aging properties like derivatives of vitamin A [7]. In the United States Aloe got popularity for the first time in 1930's based on its capability to treat the burns of X-rays [8-10]. In the recent years its extracts have been used for the treatment of stomach ulcers, canker sores and as cleansing juice by some natural health curers [11]. In the practice of naturopathy, kidney stones are prevented and treated by its juice [12]. Its plant is kept in kitchen by many mothers where it requires a little care to readily thrive in bright sunlight [13]. The gel of freshly cut inner leaf is directly applied to minor burns immediately [14]. The inner lining of leaf works as a natural and potential laxative. In a survey in 1990 Aloe vera was reported to be used by $64 \%$ population. It was found to be useful by $91 \%$ of users [15]. In the Benzoic tincture it is also one of the ingredients [16]. The genus Aloe is comprised of more than 300 species. These species are mostly native to Arabia, Madagascar and South Africa. Among these Aloe Arborescens, A. barbadensis, A. ferox, $A$. perryi and $A$. vera have high medicinal values [17]. Active ingredients are present in different concentrations in different species [18]. This genus belongs to family Xanthorrhoeaceae. A. vera is a pea-green xerophytic, arborescent or shrubby perennial plant with succulent leaves. Its leaves are long fleshy and triangular having spikes on edges. The parenchymal fleshy gel taken from the leaf centre is transparent. It is sometimes dried for the formation of Aloe vera concentrate and in other cases diluted into Aloe juicy preparations $[19,20]$. The yellow coloured flowers of the plant are not used medicinally. Laxative anthraquinones are derived from the tubules of pericycle which bound to the rind of leaf having yellowish green colour and contain liquid sticky latex [21]. This plant is indigenous to South America and South Africa. However it is under cultivation practice worldwide except rain forests, deserts and tundra. Aloe is commercially cultivated in the southern Texas, USA. This plant matures in four years and thrives for approximately twelve years [22]. Keeping in view the folk medicinal uses of the this important plant, $A$. vera, the current research work was designed to find out its phytochemical composition and its potential against the selected bacterial and fungal strains.

\section{Materials and methods Collection and identification of Aloe vera plant}

The plant was collected from the Botanical Garden of the Department of Botany, Islamia College, Peshawar, Pakistan. It was identified by the Professors of Department of Botany and confirmed with flora of Pakistan available online at Tropicos [23]. The plants were dried at room temperature and then used it further for extraction.

\section{Extraction}

0.3 grams of Aloe vera leaves grinded and added with $50 \mathrm{ml}$ of chloroform, n-hexane, ethyl acetate and double distilled water in separate flasks for phytonutrients extraction for 48 hours. These solutions were filtered by using Whattman filter paper of forty two size and the solutions were extracted. The extracts were further used for determination of various phytonutrients.

\section{Qualitative tests for phytochemicals}

Qualitative tests for Phytochemical were carried out on the different extracts and on the powdered samples. The standard methods for the identification of the components of the samples described by, Ogbuewu [24] and Trease [25] and Sofowar [26] were used. 


\section{Phlobatannins test}

The presence of phlobatannins was confirmed by the formation of red precipitate by boiling the chloroform extract of each sample with $1 \% \mathrm{HCl}$.

Flavonoid test

Ammonia solution $(5 \mathrm{ml})$ was added to a small portion of filtrate of chloroform extract followed by addition of conc $\mathrm{H}_{2} \mathrm{SO}_{4}$. A yellow colouration observed in each extract indicated the presence of flavonoids. The yellow colouration disappears on standing.

\section{Steroids test}

In this test $2 \mathrm{ml}$ of acetic anhydride and $2 \mathrm{ml}$ of $\mathrm{H}_{2} \mathrm{SO}_{4}$ were added to $5 \mathrm{ml}$ extract from each sample. Change of colour blue from violet would indicate the presence of steroids.

\section{Cardiac glycocides test}

Cardiac glycosides: Five milliliter of each sample juice was treated with two milliliter of glacial acetic acid containing one drop of $\mathrm{FeCl}_{3}$ solution, this was under layered with 1 milliliter of conc. $\mathrm{H}_{2} \mathrm{SO}_{4}$. A brown ring shows the deoxy sugar characteristics of caredenolides. Sometime a violet ring may form indicating cardiac glycoside.

\section{Tannins test}

Five milliliter of extract were taken and boiled with $20 \mathrm{ml}$ of $\mathrm{CHCl}_{3}$. On addition of $0.1 \% \mathrm{FeCl}_{3}$ solution to the filtrate and appearance of brownish colour shows the presence of tannin.

\section{Saponins test}

About five milliliter of citrus sample was taken and boiled in 20 milliliter of $\mathrm{CHCl}_{3}$ and filtered. To the 10 milliliter filtrate added five milliliter of double distilled water with 3 drops of olive oil, emulsion formation shows the presence of saponins.

\section{Terpenoids test}

Five milliliter of the sample was added to 2 milliliter of $\mathrm{CHCl}_{3}$ and three milliliter of conc. $\mathrm{H}_{2} \mathrm{SO}_{4}$. The formation of reddish brown colour would show the presence of terpenoids.

\section{Results and discussion}

Sample A

Finding of these experiments are shown in (Table 1) and described as follows.

Table 1. Phytochemicals screening tests for sample A

\begin{tabular}{|c|c|c|c|c|c|c|c|}
\hline 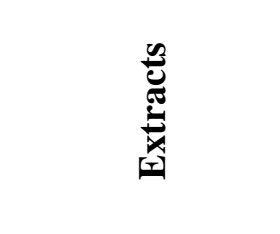 & 栉 & 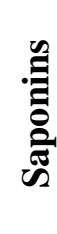 & 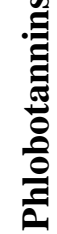 & 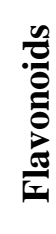 & 䎹 & $\frac{\mathscr{0}}{0}$ & 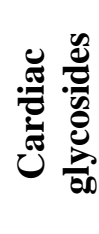 \\
\hline Chloroform & + & + & - & + & + & + & + \\
\hline d. distilled water & + & + & - & + & - & + & - \\
\hline Ethyl acetate & + & + & - & + & + & + & + \\
\hline n-Hexane & + & + & - & - & + & + & + \\
\hline
\end{tabular}

\section{Chloroform extract tests}

The test was performed on chloroform extract; the results for tannins, saponins, terpenoids, flavonoids, cardiac glycosides and steroids were positive and for phlobotannins were negative.

\section{n-Hexane extracts test}

This test was performed on n-hexane and the results for tannins, saponins, cardiac glycosides, steroids and terpenoids were positive and for phlobotannins and flavonoids were negative. 
Ethyl acetate extract tests

Ethyl acetate extract was used for this test and the results for tannins, flavonoids, saponins, steroids, terpenoids, and cardiac glycosides were positive and for phlobotannins were negative.

Double distilled water extract tests
Double distilled water was used to perform this test and the results for tannins, saponins, flavonoids and terpenoids were positive and for phlobotannins, steroids was negative.

\section{Sample B}

Finding of these experiments are shown in (Table 2) and described as follows.

Table 2. Phytochemicals screening tests for sample B

\begin{tabular}{|c|c|c|c|c|c|c|c|}
\hline 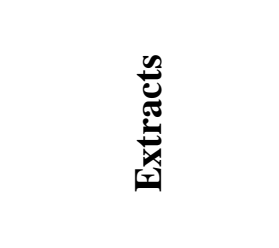 & 栉 & 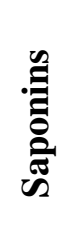 & 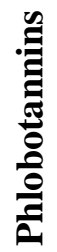 & $\begin{array}{l}\frac{n}{0} \\
\frac{0}{0} \\
\frac{0}{0} \\
\frac{\pi}{L}\end{array}$ & 晜 & & 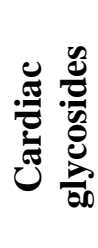 \\
\hline Chloroform & + & + & - & + & + & + & - \\
\hline d. distilled water & + & + & - & - & - & + & - \\
\hline Ethyl acetate & + & + & - & - & - & + & + \\
\hline n-Hexane & + & + & - & - & - & - & + \\
\hline
\end{tabular}

\section{Chloroform extract tests}

In these tests chloroform extract was used and the results for tannins, saponins, flavonoids steroids, terpenoids, were positive and for phlobotannins and cardiac glycosides were negative.

\section{n-Hexane extract tests}

n-hexane was employed in these tests and the results for tannins, saponins, and cardiac glycosidic were positive and for phlobotannins, flavonoids, steroids, terpenoids were negative.

\section{Ethyl acetate extracts tests}

Ethyl acetate extract was used to get results for tannins, saponins, terpenoids cardiac glycosidic were positive, and for phlobotannins, flavonoids and steroids were negative.

\section{Double distilled water extract tests}

Double distilled water was used and the results for tannins, saponins, and terpenoids were positive and for flavonoids, phlobotannins steroids and cardiac glycosides were negative.

\section{Anti-microbial activities}

For the antimicrobial activity determination the solvents methanol and ethanol were used. The extract was prepared from leaves which were cleaned with water and after that dried in shade. An electric blender was used to grind the material into powder form. All this process was carried out in PCSIR lab Peshawar.

For filtration the extracts were filtered using Whattman filter paper. The filtrate after collection was shifted to rotary evaporator. In rotary evaporator the extract solution was collected less than $45^{\circ} \mathrm{C}$ of temperature.

The water contents of the residue were further dried on water bath at less than $60^{\circ} \mathrm{C}$ temperature. Sterile bottles were used for storage of crude extract of plants under refrigerator for further use of antimicrobial tests.

The microorganism for antimicrobial tests included four gram negative bacterial strains, three gram positive bacterial strains and one fungal strain effects were investigated. 
Gram +ive strains: Staphlyococus aureus, Bacillus atrophoeus and Bacillus subtilis.

Gram -ive strains: Escherichia coli, Kleibsiella pneumoniae, Salmonila typhi.

Fungal Strains: Aspergillus flavus, Aspergillus Niger and Candida albicans.

Nutrient agar culturing media was utilized. Such media was utilized for the shaking, inoculation, incubation as well as for standardization and proper growth of microorganism.

The antibiotic Azithromycin 50Micro grams /six $\mu \mathrm{l}$ for gram positive bacteria, Ciprofloxacin 30 Micro grams /six $\mu$ for Gram negative bacteria and Ciprofloxacin and erythromycin 50 Micro grams /six $\mu$ l for fungal strain of Candida albicans, Staphlyococus aureus, and Bacillus subtilis were utilized.

\section{Disc diffusion method}

Disc diffusion method was utilized for antimicrobial activity. The $0.5 \mathrm{Mc}$ farland standards were for bacterial culture (Aida $e t$ al., 2001). Discs prepared from filter paper impregnated with plant extracts of six and twelve micro liters samples were applied on plate's discs.

\section{Antimicrobial activity determination}

On the first day nutrient dissolved agar medium (2.8 gram $/ 100$ milliliter) plus nutrient broth (1.3 gram /100 milliliter) in double distilled water were added in flasks. The broth media of 20 milliliter of was added in test tubes. For avoiding contamination agar media were poured into plates placed in incubator under laminar flow. All the apparatus were sterilized at $121{ }^{\circ} \mathrm{C}$. On next day the stock microbial culture were freshed and were streaked on the nutrient agar plates under laminar flow, and further incubated at $37^{\circ} \mathrm{C}$ for other twenty four hours.
On third day the fresh streak were further reinoculated and again incubated the culture plates. On $4^{\text {th }}$ day the cultures were inoculated to flask media and shaken at 200rpm overnight. The $5^{\text {th }}$ day the flasks contained cultures were diluted and spread out on plates and kept in refractor for twenty minutes [27, 28]. After 20minutes Whattman filter paper disc were located on plates through forceps under luminar flow and plants parts extracted with dimethyl sulfoxide solvent were spotted applied on every plats disc. At last day of experiment the zone of inhibition were marked around the disc and make a snapshot the photos for zone of inhibition.

Antibacterial Activity: A total of four bacterial strains of were tested for plant extract which are Streptococcus aureus, $B$. subtilis, B. cereus, E. coli, P. aeruginosa and $S$. typhi. The reference fungal strain was C. albicans. Antibacterial activity and antibacterial activity results of Aloe vera are shown in (Table 3; Fig. 1 \& Table 4; Fig. 2) respectively. The activities of Aloe vera extract against gram positive bacteria are very effective with respect to standard drug of Ciprofloxacin and erythromycin. Similarly gram negative microbes were tested but were not very susceptible except K. pneumonia.

\section{Antifungal activity}

Antifungal activities for Aloe vera extract were tested against two fungal strains which were Aspergillus flavus and Aspergillus niger. The most prominent activity was shown in ethanolic $(11 \pm 0.53$ and $10 \pm 0.32$ and acetonic extract disc of plant extract. The maximum antifungal activities were observed in acetone extract disc $(15 \pm 0.73$ and $8 \pm 0.37$ ) other than aqueous extract (0.00 and 0.00) and for ethanol extract was $(11 \pm 0.53$ and $10 \pm 0.32)$. 
Table 3. Antibacterial activity of decoction of Aloe vera in paper disc method [28]

\begin{tabular}{|c|c|c|c|c|c|}
\hline \multirow{2}{*}{ Bacteria } & \multicolumn{5}{|c|}{ Zone of Inhibition (mm) } \\
\cline { 2 - 6 } & \multicolumn{5}{|c|}{ Sample concentration in ml } \\
\cline { 2 - 6 } & A & B & DMSO & Ciprofloxacin & Erythromycin \\
\hline K. pneumoniae & $8.0 \pm 0.2$ & $14.5 \pm 0.2$ & - & $27 \pm 0.02$ & - \\
\hline S. typhi & 0 & 0 & - & $8 \pm 0.01$ & - \\
\hline P. aeruginosa & 0 & 0 & - & $15 \pm 0.02$ & - \\
\hline E. coli & 0 & 0 & - & $31 \pm 0.02$ & - \\
\hline S. aureus & $33.5 \pm 0.1$ & $36.5 \pm 0.1$ & - & - & $26.9 \pm 0.03$ \\
\hline B. subtilus & $10.00 \pm 0.1$ & $15.5 \pm 0.3$ & - & - & $27 \pm 0.02$ \\
\hline B. cereus & $9.0 \pm 0.2$ & $15.2 \pm 0.1$ & - & - & $25 \pm 0.01$ \\
\hline
\end{tabular}

Data represent mean of three individual studies

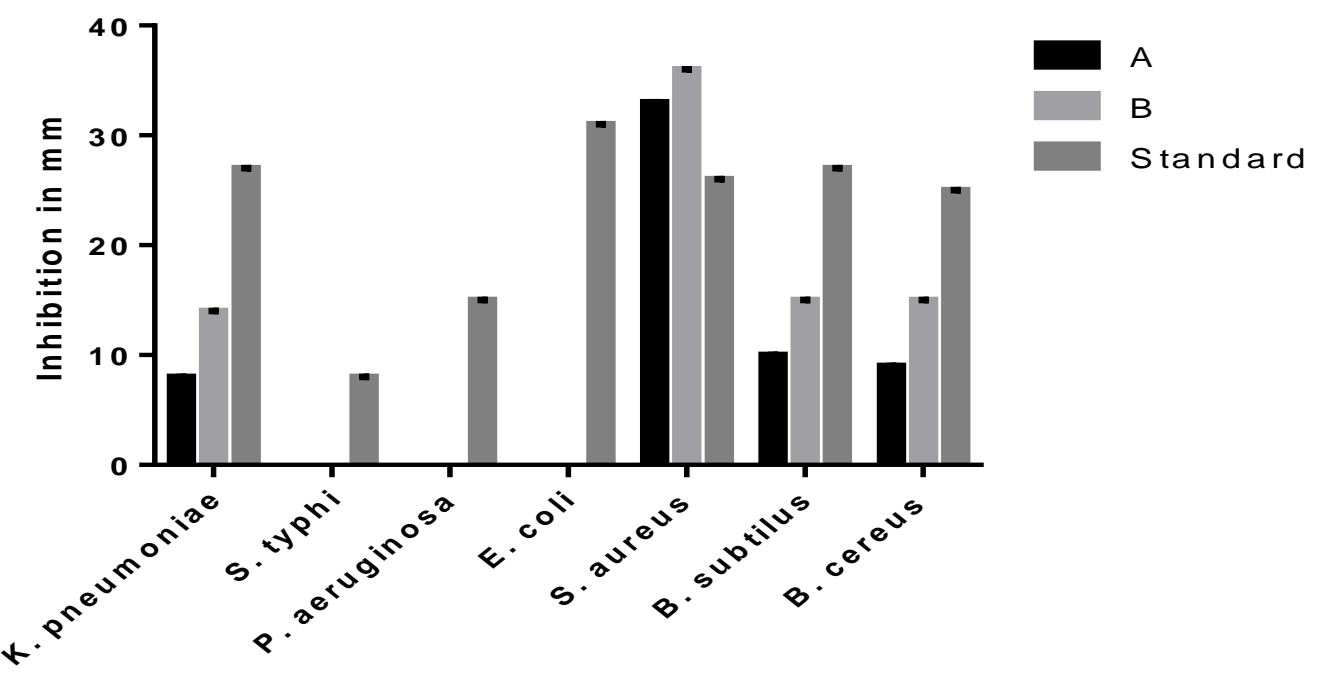

Figure 1. Antibacterial activity of decoction of Aloe vera in paper disc method

Table 4. Antibacterial activity of decoction of Aloe vera in agar well method $[29,30]$

\begin{tabular}{|c|c|c|c|c|c|}
\hline \multirow{2}{*}{ Bacteria } & \multicolumn{5}{|c|}{ Zone of Inhibition (mm) } \\
\cline { 2 - 6 } & \multicolumn{5}{|c|}{ Sample concentration in ml } \\
\cline { 2 - 6 } & A & B & DMSO & Ciprofloxacin & Azthromycin \\
\hline K. pneumoniae & $11.0 \pm 0.01$ & $16.5 \pm 0.2$ & - & $27 \pm 0.02$ & - \\
\hline S. typhi & 0 & 0 & - & $8 \pm 0.01$ & - \\
\hline P. aeruginosa & 0 & 10 & - & $15 \pm 0.02$ & - \\
\hline E. coli & 0 & 0 & - & $31 \pm 0.02$ & - \\
\hline S. aureus & $38.5 \pm 0.01$ & $40.5 \pm 0.02$ & - & - & $26.9 \pm 0.03$ \\
\hline B. subtilus & $15.5 \pm 0.02$ & $17.5 \pm 0.01$ & - & - & $27 \pm 0.02$ \\
\hline B. cerus & $12.5 \pm 0.02$ & $14.5 \pm 0.03$ & - & - & $25 \pm 0.01$ \\
\hline
\end{tabular}

Data represent mean of three individual studies 


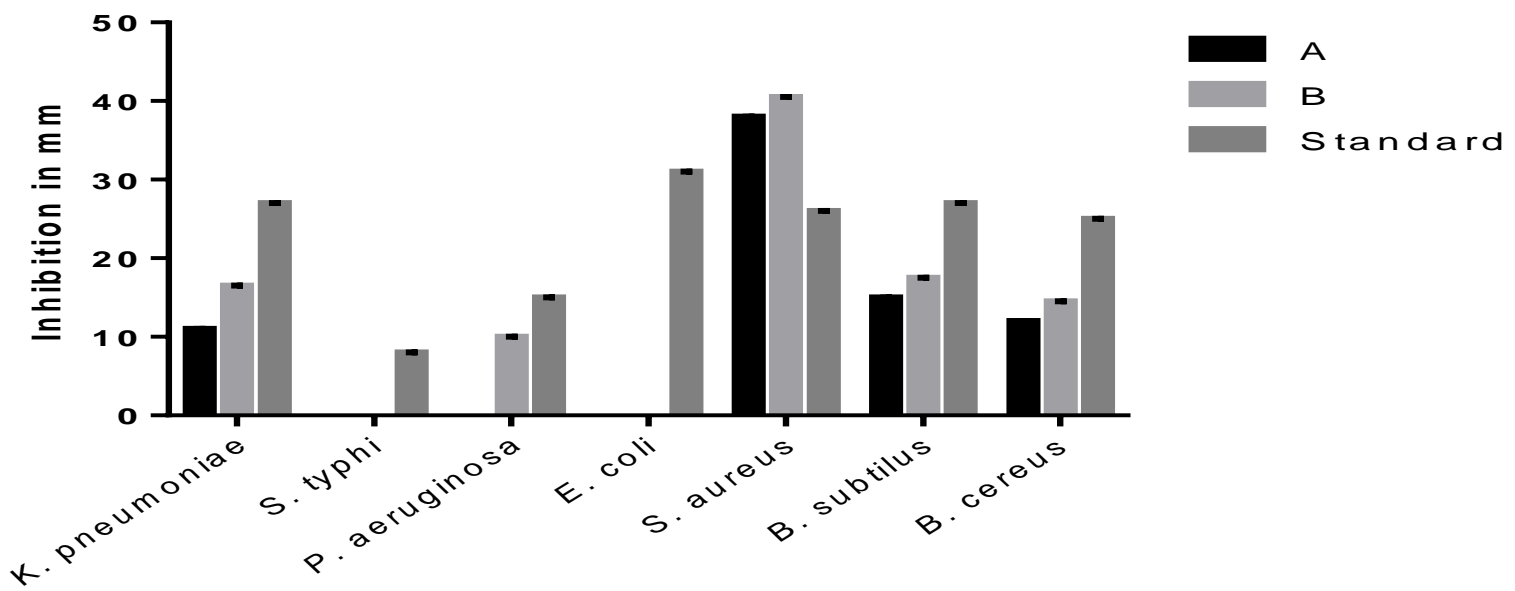

Figure 2. Antibacterial activity of decoction of Aloe vera in agar well method

\section{Conclusion}

The present study of phytochemical was carried out on two species of Aloe vera leaves obtained locally from garden of Islamia College, Peshawar, Pakistan. The sample revealed the presence of medicinally active constituents like tannins, saponins, phlobbasstannis, steroid, terpenoids, flavonoids, and cardiac glycosides. These phytochemicals were investigated. For the investigation of each phytochemical, specific tests were conducted which confirm the presence or absence of phytochemical. All the tests were carried out with different solvents extracts such as water, ethanol, chloroform, methanol etc. Then the tests were carried out with all solvents extracts for the confirmation of phytochemicals. Similarly the leaves of two species of Aloe vera antimicrobial studies effects were investigated which shows potent effects against some gram positive bacteria such as Staphlyococus aureus, Bacillus subtilis, Bacillus atrophoeus some gram negative bacterial strains such as Escherichia coli ,Kleibsiella pneumonia and Salmonila typhi.similarly its ethanolic and acetonic extract were also very susceptible to fungal strains like Aspergillus flavus and Aspergillus niger and Candida albicans.

Authors' contributions
Conceived and designed the experiments: B Raad \& SS Ali, Performed the experiments: B Raad, SS Ali \& KU Rehman, Analyzed the data: N Akhtar, B Ullah \& S Wali, Contributed materials/ analysis/ tools: SS Ali, KU Rehman \& N Akhtar, Wrote the paper: B Raad, B Ullah \& S Wali.

\section{Acknowledgment}

The authors are thankful to Higher Education Commission of Pakistan for providing financial support to carry out this research work.

\section{References}

1. Shelton RM (1991). Aloe vera: its chemical and therapeutic properties. Int $J$ Dermatol 30: 679-83.

2. Haller JA (1990). Drug for all seasons: medical and pharmacological history of Aloe. Bull NY Acad Sci 66.

3. Atherton P (1998) Aloe vera: magic or medicine. Nurs Stand 12: 49-54.

4. Bensky D, Gamble A \& Kaptchuk TJ (1993). Chinese herbal medicine: Materia Medica. Seattle, Wash.: Eastland Press xxv 556.

5. Ghazanfar SA (1994). Handbook of Arabian medicinal plants. Boca Rato: CRC Press.

6. Grindlay D, Reynolds T (1986). The Aloe vera phenomenon: a review of the 
properties and modern uses of the leaf parenchyma gel. $J$ Ethnopharmacol 16:117-51.

7. Danhof I (1993). Potential reversal of chronological and photo-aging of the skin by topical application of natural substances. Phytotherapy Res 7: S53-S56.

8. Rowe T (1940). Effect of fresh Aloe vera in the treatment of third degree roentgen reactions on white rats. J Am Pharm Assoc 29: 348 .

9. Rowe T (1941). Further observations on the use of Aloe vera leaf in the treatment of third degree x-ray reactions. $J A m$ Pharm Assn 30: 266.

10. Lewis WH (1977). Medical botany: plants affecting man's health. New York: Wiley.

11. McGuffin M, Hobbs $\mathrm{C}$, Upton $\mathrm{R} \&$ Goldberg A (1997). American Herbal Products Association's Botanical Safety Handbook. Boca Raton. New York: CRC Press 231.

12. Murray MT \& Pizzorno JE (1991). An Encyclopedia of Natural Medicine. Rocklin, CA: Prima Publishing.

13. Duke JA (1997). Green Pharmacy. Emmaus, PA: Rodale Press. 507.

14. Ship A (1977). Is topical Aloe vera plant mucus shelpful in burn treatment? JAMA 238:1770.

15. Brown JS, Marcy SA (1991). The use of botanicals for health purposes by members of a prepaid health plan. Res Nurs Health 14: 339-350.

16. Robbers JE, Speedie MK \& Tyler VE (1996). Pharmacognosy and Pharmacobio-technology. Baltimore: Williams \& Wilkins IX, 337.

17. Inan $A$, Sen $M$, Koca $C$, Ergin $M$ \& Dener C. 2007. Effect of Aloe vera on colonic anastomoses of rats. Surgical Practice 11(2): 60-65.

18. Bozzi, ACP, Austin S \& Vera FA (2007). Quality and authenticity of commercial aloe vera gel power. Food Chem 103(1): 22-30.
19. Kapoor LD (1990). CRC handbook of ayurvedic medicinal plants. Boca Raton: CRC Press.

20. Ross IA (1999). Medicinal plants of the world: chemical constituents, traditional, and modern medicinal uses. Totowa, NJ Humana Press XI 415.

21. Schulz V, Hansel R \& Tyler VE (1997). Rational Phytotherapy: A Physicians' Guide to Herbal Medicine. Berlin: Springer 306.

22. Foster S (1999). Aloe. Herbs for Health 59-60.

23. http://www.tropicos.org/Name/40010612 ?projectid $=32$

24. Ogbuewu IP (2008). Physiological responses of rabbits fed graded levels of neem (Azadirachta indica) leaf meal. M.Sc. Thesis, Federal University of Technology, Owerri.

25. Harborne JB (1973). Phytochemical Methods, a guide to modern techniques of plant analysis $4^{\text {th }}$ ed, 1-5: 182-91.

26. Sofowora A (1993). Medicinal plants and Traditional Medicine in African Spectrum Book Ltd. University of Ife Press Nigeria, pp.119.

27. Fazli M, Bjarnsholt T, Kirketerp-Møller K, Jørgensen B, Andersen AS, Krogfelt KA, Givskov M, Tolker-Nielsen T. (2009). Nonrandom distribution of Pseudomonas aeruginosa and Staphylococcus aureus in chronic wounds. J Clin Microbiol 47: 4084-4089.

28. Rehman KU, Wali S, Akhtar N, Ullah B, Afzal S, Ahmad I \& Hamayun M (2019). Evaluation of the antibacterial and antifungal potential of spider saxifrage plant (Saxifraga flagellaris Willd.). Pure Appl Biol 8(2): 1163-1171.

29. Ashok M (2002). Home remedies in Ayurveda, Amar Granth Publications, Delhi, pp 390.

30. Neu HC (1987). In vitro activity of a new broad spectrum, beta-lactamase-stable oral cephalosporin, cefixime. Pediatr Infect Dis J 6(10): 958-62. 